\title{
Caracterização da prescrição de atividade física: Os direitos autorais enquanto possibilidade na modelagem da seção de treinamento
}

\author{
Characterization of physical activity prescription: Copyright as a possibility in the modeling of the
} training section

Caracterización de la prescripción de actividad física: El copyright como posibilidad en la modelización del apartado de formación

Recebido: 02/06/2021 | Revisado: 10/06/2021 | Aceito: 16/06/2021 | Publicado: 30/06/2021

Tiago de Melo Ramos

ORCID: https://orcid.org/0000-0002-6500-557X AGES Faculdade de Ciências Humanas e Sociais, Brasil

E-mail: tiagoed.f@hotmail.com

Jaldemir Santana Batista Bezerra

ORCID: https://orcid.org/0000-0003-4526-4408

AGES Faculdade de Ciências Humanas e Sociais, Brasil

E-mail: jaldemirbatista@ hormail.com

Maique dos Santos Bezerra Batista

ORCID: https://orcid.org/0000-0002-6117-4034

AGES Faculdade de Ciências Humanas e Sociais, Brasil

E-mail: maique-bezerra@hormail.com

Antenor de Oliveira Silva Neto

ORCID: https://orcid.org/0000-0003-4787-7566

Universidade Tiradentes, Brasil

E-mail: antenor_oliveira@unit.br

Wendel Fren Costa dos Anjos

ORCID: https://orcid.org/0000-0002-5495-9167

Centro Universitário Planalto do Distrito Federal, Brasil

E-mail:wendel_ef@hotmail.com

Robélius De Bortoli

ORCID: https://orcid.org/0000-0003-1231-6451

Universidade Federal de Sergipe, Brasil robelius@academico.ufs.br

\begin{abstract}
Resumo
O profissional de Educação Física, em essência, planeja, desenvolve, organiza, constrói, executa e estrutura modelos e seções de treinamento, dominando conceitos e procedimentos relacionados ao corpo, saúde e atividade física. $\mathrm{Na}$ elaboração do programa de treinamento são levados em consideração aspectos relacionados à individualidade do aluno / paciente, fatores socioeconômicos, estado geral de saúde e o objetivo e finalidade da prática da atividade. No ato e exercício de sua profissão, ele produz e aplica produtos que são fruto de sua intelectualidade e, na construção desse produto, apresenta critérios e características relacionadas ao direito autoral. Existem elementos característicos da resolução CONFEF n $n^{\circ} 327 / 2016$ que corroboram os critérios da Lei $n^{\circ}$ (9609/98) sobre direitos autorais no Brasil. Partindo dessa premissa, este artigo objetivou identificar se, no exercício de sua profissão, o profissional de Educação Física elabora um produto passivo para proteção de direitos autorais, bem como conhecer as características e critérios na prescrição de atividade física. Como problema, vale perguntar se o profissional de Educação Física constrói um produto em seu trabalho e se esse produto está sujeito à proteção de direitos autorais. No campo metodológico, foram utilizados princípios da pesquisa documental, analisando e comparando a resolução CONFEF no 327/2016 e a LEI $n^{\circ}$ (9609/98). Foram obtidas as seguintes informações: há relação entre os programas de treinamento e a proteção de direitos autorais; O profissional de Educação Física exige uma ação passiva de discussão contra a proteção dos direitos autorais. É necessário aprofundar o debate sobre a prescrição de atividade física, educação física profissional e direitos autorais.
\end{abstract}

Palavras-chave: Prescrição de treinamento; Direitos autorais; Produto e atividade física.

\begin{abstract}
The Physical Education professional in essence plans, elaborates, organizes, builds, executes and structures models and training sections, masters concepts and procedures related to the body, health and physical activity. In preparing the training program, it takes into account aspects related to the individuality of the student / client, socioeconomic factors, health in general, objective and purpose with the practice of the activity. In the act and exercise of his profession, he applies intellectual property, and in the construction of his product he presents criteria and
\end{abstract}


characteristics related to copyright. There are characterizing elements in CONFEF Resolution No. $327 / 2016$ that corroborate the criteria of LAW No. 9,609 / 98 of copyright in Brazil. Based on this premise, this article aimed to identify whether, in the exercise of their profession, the Physical Education professional develops a passive product of copyright protection, as well as to know the characteristics and criteria in the prescription of physical activity. While problematic, it is worth noting whether the Physical Education professional builds a product and if that product fits the protection of copyright. In the methodological field, principles of documentary research were used, analyzing and comparing CONFEF Resolution No. 327/2016 and LAW No. 9.609 / 98. Obtaining the following information, there is a relationship between training programs and copyright protection; the Physical Education professional demands passive action for discussion in the face of copyright protection; there is a need to deepen the discussion regarding the prescription of physical activity, physical education professional and copyright.

Keywords: Training prescription; Copyright; Product and physical activity.

\section{Resumen}

El profesional de Educación Física, en esencia, planifica, elabora, organiza, construye, ejecuta y estructura modelos y secciones de entrenamiento, dominando conceptos y procedimientos relacionados con el cuerpo, la salud y la actividad física. En la elaboración del programa de entrenamiento se tiene en cuenta aspectos relacionados con la individualidad del alumno / paciente, factores socioeconómicos, salud en general, y el objetivo y finalidad de la práctica de la actividad. En el acto y ejercicio de su profesión, él produce y aplica productos fruto de su intelectualidad $\mathrm{y}$, en la construcción de esto producto, presenta criterios y características relacionados con los derechos de autor. Hay elementos característicos en la resolución de la CONFEF n 327/2016 que corroboran los criterios de la Ley $n^{\circ}$ (9609/98) de derechos de autor en Brasil. Partiendo de esta premisa, este artículo tuvo como objetivo identificar si, en el ejercicio de su profesión, el profesional de Educación Física elabora un producto pasivo para la protección de los derechos de autor, así como conocer las características y criterios en la prescripción de actividad física. Como problema, vale la pena preguntarse si el profesional de Educación Física construye un producto en su trabajo y si este producto es pasible de protección por derechos de autor. En el campo metodológico se utilizaron principios de investigación documental, analizando y comparando la resolución CONFEF no $327 / 2016$ y la LEY n ${ }^{\circ}$ (9609/98). Se obtuvo la siguiente información: existe una relación entre los programas de formación y la protección de los derechos de autor; el profesional de Educación Física exige una acción pasiva de discusión contra la protección de los derechos de autor; Es necesario profundizar el debate sobre la prescripción de actividad física, educación física profesional y derechos de autor.

Palabras clave: Prescripción de entrenamiento; Derechos de autor; Producto y actividad física.

\section{Introdução}

A prática regular de atividade física sistematizada proporciona inúmeros benefícios para o praticante. Manter um comportamento ativo é fundamental para prevenção de doenças relacionadas à inatividade física, além de ser fundamental para manutenção do estado de saúde. Porém, sem as devidas orientações, acompanhamento e projeto de treinamento pode apresentar riscos aos praticantes.

Nesta respectiva, o profissional de Educação Física se torna essencial em todo o processo que envolve a prática de atividade física sistematizada. E suas funções estão além do mero ato de orientar ou acompanhar o praticante, seus esforções estão intrinsicamente ligados à percepção das características individuais de cada cliente/aluno, aplicar saberes como cinesiológicos, fisiológicas, teorias de treinamento entre outro para assim chegar ao produto final, alcançar o projeto de treinamento, a seção de trabalho, a periodização do sujeito praticante. Sendo esse o instrumento que vai direcionar todas as ações do requerente dos serviços.

Logo, tomando como base essa variante no processo de atuação do profissional de Educação Física, se faz necessário refletir sobre os presentes pontos determinar implicações técnicas para a proteção das prescrições de atividades físicas. A prescrição gera um produto? O produto contém os elementos técnicos de prescrição? Quais as informações do cliente na prescrição? Quais os objetivos do cliente? Prevenção ou profilático? Reavaliações, elementos científicos para montar a prescrição? Início e fim da prescrição? Qual a dose da atividade física sistematizada? Essas são indagações que estão sendo discutidas no presente estudo e norteiam os interesses da pesquisa. 


\section{Objetivo}

Caracterizar a prescrição da atividade física, seus elementos, processos, etapas e finalidade.

Analisar e comparar a lei $\mathrm{N}^{\circ}$ 9.609/98 de direitos autorias e o que lhe são conexos com a resolução CONFEF ${ }^{\circ}$ 327/2016 que versa sobre as responsabilidades do profissional de Educação Física na prescrição de atividade física.

\section{Metodologia}

A presente pesquisa está sedimentada no campo da pesquisa básica, pois, aborda uma discussão sobre a atuação do profissional de Educação Física tomando como norte as leis e resoluções que regem a profissão no Brasil, além levantar reflexão sobre a proteção autoral dos produtos frutos da ação dos profissionais de Educação Física. Quanto ao objetivo se aplicou elementos da pesquisa descritiva e explicativa, onde inicialmente se fez necessário descrever e apresentar o perfil do profissional de Educação Física previsto na lei No 9.609/98 e resolução CONFEF nº 327/2016. Em seguida, discussão e relação da atuação do profissional de Educação Física com a Lei $N^{\circ}$ (9609/98) de direitos autorais. Já na esfera discursiva, a pesquisa é caracterizada como qualitativa, pois as informações coletadas foram organizadas e discutidas tomando como base análise interpretativa (Minayo, 1989).

Seguindo os princípios da pesquisa documental foi aplicado a técnica de análise documental para a sistematização e construção dos princípios do presente estudo. Inicialmente se fez necessário realizar um levantamento bibliográfico com as seguintes palavras-chave: atividade física, prescrição de atividade física, modelagem de projeto e profissional de Educação Física. Esta busca foi realizada no https://scholar.google.com/schhp?hl=pt-BR

Enquanto critério de inclusão do estudo, optou-se por análise do tema e resumo, sendo selecionado trabalhos que versam sobre as palavras-chave aqui destacadas. Em seguida, no trato documental foi realizado uma análise da lei $\mathrm{N}^{\circ}$ 9.609/98 e resolução CONFEF n ${ }^{\circ} 327 / 2016$, especificando e detalhando o artigo $8^{\circ}$ da lei dos direitos autorais e $o$ artigo $8^{\circ}$ da resolução que versa sobre as funções do profissional de Educação Física. Finalmente, a lei e resolução foram analisadas e comparadas, buscando identificar elementos de similaridades entre o produto gerado pelo profissional de Educação Física e os direitos autorais.

\section{Resultados e Discussão}

Conceitualmente, pode-se inferir que os direitos autorais estão relacionados aos gozos proporcionados a autores, inventores, intelectuais, titulares dos direitos ou proprietário da propriedade intelectual que fora desenvolvida. E esse benefício será concedido por um espaço de tempo, sendo possível ainda que familiares usufruam dos direitos do autor. Destaca-se também que através da lei dos direitos autorais é possível requisitar os direitos conexos, em que organizações de radiodifusão, produtores fonográficos e intérpretes recebem os devidos créditos por seu produto/criação (PanzolinI, 2018).

Em destaque mundial, podemos citar a convenção de Berna, enquanto ação estrutural para o conceito e regras determinadas para a proteção dos direitos autorais, visando a valorização da propriedade intelectual. A convenção de Berna foi fundamental também para a sistematização da Lei $\mathrm{N}^{\circ}$ (9609/98), que regulamenta e estrutura os direitos autorais e direitos conexos no Brasil (Leroy, 2020). É por meio desta lei que se busca investigar a possibilidade dos profissionais em Educação Física de terem sua propriedade intelectual assegurada na lei dos direitos do autor e o que lhes for conexo.

Em sua atuação o profissional de Educação Física pode exercer diversas funções com objetivos e finalidades distintas, desde a prevenção a fins profiláticos. Para tanto, é relevante considerar alguns aspectos sobre o cliente, aluno e/ou atleta, como idade, biotipo corporal, objetivos e finalidades desse com o programa e orientação de atividade física (Luna \& Rocha, 2020). É neste momento que é exigido resiliência frente aos saberes aplicados para a periodização do programa e seção e modelagem da 
atividade a ser desenvolvida. Uma vez que, primariamente, neste campo é que existe a necessidade de estabelecer as especificidades para o programa de atividade desejada.

Logo, o profissional de Educação Física, que será chamado aqui de PEDF, aplica seus saberes ou propriedade intelectual e, possivelmente, gera um produto no desenvolvimento da seção de treinamento, e essa pode ser passiva de proteção nos direitos autorais. Em sua função, o PEDF trabalha com um objeto de estudo que é a atividade física, elemento abordado em sequência.

A Atividade Física pode ser conceituada como ações motoras realizadas pelo homem que exigem ou proporcionam gastos energéticos, sejam com fins de lazer, esporte ou saúde (Lopes; et al, 2017). Na atualidade, existem inúmeros estudos que relacionam a prática de atividade física regular como responsável por alterações significativas no estado de saúde dos praticantes, além de proporcionar a manutenção da saúde.

Citando alguns desses estudos é possível responsabilizar a atividade física a benefícios e combate de mazelas, como: envelhecimento saudável (Matsudo \& Matsudo, 2008), combate à depressão (Costa, et al 2007), controle da diabetes de mellitus (Mercuri \& Arrechea,2001), pressão arterial (Medina, 2010), hipertensão (Magalhães, 2017), tratamento de câncer (GurgeL; et al, 2018), doenças cardiovasculares (Estrela \& Bauer, 2017), impactos positivos na gestação e lactação (Carmo, 2018 ), combate à obesidade (Dias; et al, 2017) e associação recentemente à prevenção contra a COVID-19 (Souza \& Tritany, 2020). Tais estudos sustentam a relevância da prática regular de atividade física e abordam ainda a necessidade da construção de seções de treinamentos específicas e individualizadas, as quais serão abordadas aqui como exercícios.

O exercício físico deve ser entendido como subproduto ou categoria da atividade física, em sua sistematização existe a necessidade de planejar, controlar variantes como volume e intensidade, ser individualizado e elaborado por um PEDF (Roschel \& Ugrinowitsch, 2011). Tal prática possui em sua essência fins relacionados aos objetivos dos clientes e praticantes, podendo ser condicionada a prática esportiva, saúde, lazer, condicionamento físico e/ou perspectivas profiláticas e terapêuticas.

Com relação a sua orientação, acompanhamento e prescrição no Brasil, compete ao PEDF aplicar os princípios do treinamento científico, direcionar o volume, período, intensidade, avaliação, definir métodos, estruturar, modelar, organizar, monitorar e remodelar as seções de acordo com as adaptações corporais frente aos estímulos do treinamento (Confef, 2009).

Evidenciado os conceitos de atividade e exercício é momento de caracterizar como se dá o processo de modelagem das seções de treinamento e em seguida comparar com os critérios abordados na Lei $\mathrm{N}^{\circ}$ (9609/98) de direitos autorais no Brasil. No Quadro 1 é apresentado os elementos caracterizadores na seção do treinamento, seguindo as normas e determinações do conselho regional de Educação Física. 
Quadro 1 - Competências e Funções do Profissional de Educação Física".

Resolução CONFEF no 327/2016: Art. 2º - Especialista em Treinamento Esportivo/Físico é o Profissional de Educação Física que conhece em profundidade as bases teóricas e metodológicas desta especialidade, aplicando-as nos processos de treino das diferentes modalidades esportivas

Função e aplicação do saber: planejamento, promoção, desenvolvimento, manutenção e recuperação do condicionamento e das capacidades físicas, quer na orientação individual e/ou coletiva;

\begin{tabular}{|c|c|c|c|c|c|}
\hline Características & Características & Características & Características & Características & Características \\
\hline $\begin{array}{l}\text { Art. } 3 \\
\text { I- }\end{array}$ & $\begin{array}{l}\text { Art. } 3 \\
\text { II- }\end{array}$ & $\begin{array}{l}\text { Art. } 3 \\
\text { III- }\end{array}$ & $\begin{array}{l}\text { Art. } 3 \\
\text { IV- }\end{array}$ & $\begin{array}{l}\text { Art. } 3 \\
\text { V- }\end{array}$ & $\begin{array}{l}\text { Art. } 3 \\
\text { VI- }\end{array}$ \\
\hline $\begin{array}{l}\text { conhecer e aplicar } \\
\text { os princípios } \\
\text { científicos do } \\
\text { treinamento: } \\
\text { Individualidade, } \\
\text { Adaptação, } \\
\text { Sobrecarga, } \\
\text { Continuidade e } \\
\text { Interdependência } \\
\text { Volume- } \\
\text { Intensidade, } \\
\text { observando suas } \\
\text { relações nos } \\
\text { diferentes níveis } \\
\text { de rendimento } \\
\text { físico individual } \\
\text { e/ou coletivo no } \\
\text { esporte e/ou em } \\
\text { outros programas } \\
\text { de atividades } \\
\text { físicas orientados } \\
\text { por Profissionais } \\
\text { de Educação } \\
\text { Física; }\end{array}$ & 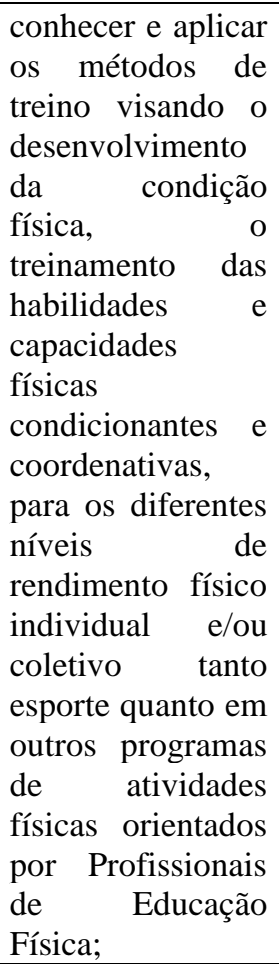 & $\begin{array}{l}\text { conhecer e aplicar } \\
\text { os componentes da } \\
\text { carga (volume, } \\
\text { intensidade e } \\
\text { densidade) e suas } \\
\text { relações com os } \\
\text { processos } \\
\text { adaptação de } \\
\text { organismo humano } \\
\text { ao esforço físico } \\
\text { para os diferentes } \\
\text { níveis } \\
\text { rendimento físico } \\
\text { individual e/ou } \\
\text { coletivo tanto no } \\
\text { esporte, quanto em } \\
\text { outros programas } \\
\text { de atividades } \\
\text { físicas orientados } \\
\text { por Profissionais } \\
\text { de } \\
\text { Física; Educação }\end{array}$ & $\begin{array}{l}\text { planejar, } \\
\text { estruturar } \\
\text { organizar } \\
\text { processo } \\
\text { treinamento, de } \\
\text { definindo as } \\
\text { unidades de } \\
\text { treino micro, } \\
\text { meso e macro- } \\
\text { ciclo, para os } \\
\text { diferentes níveis } \\
\text { de rendimento } \\
\text { físico individual } \\
\text { e/ou coletivo } \\
\text { tanto no esporte, } \\
\text { quanto } \\
\text { outros em } \\
\text { programas de } \\
\text { atividades } \\
\text { físicas } \\
\text { orientados por } \\
\text { Profissionais de } \\
\text { Educação Física; }\end{array}$ & $\begin{array}{l}\text { planejar, } \\
\text { promover, } \\
\text { desenvolver, } \\
\text { manter } \\
\text { recuperar a } \\
\text { condição/forma } \\
\text { física de acordo } \\
\text { com os } \\
\text { princípios } \\
\text { científicos do } \\
\text { treinamento e da } \\
\text { periodização do } \\
\text { treino: períodos } \\
\text { e etapas de } \\
\text { treino, efeitos } \\
\text { dos diferentes } \\
\text { componentes do } \\
\text { treino, } \\
\text { magnitudes das } \\
\text { cargas de treino } \\
\text { e ras } \\
\text { adequações às } \\
\text { condições } \\
\text { individuais; }\end{array}$ & $\begin{array}{l}\text { Analisar objetivos, } \\
\text { conteúdos e efeitos } \\
\text { do treinamento, } \\
\text { assim como as suas } \\
\text { indicações } \\
\text { contraindicações, } \\
\text { para os diferentes } \\
\text { níveis de rendimento } \\
\text { físico individual e/ou } \\
\text { coletivo tanto no } \\
\text { esporte quanto em } \\
\text { outros programas de } \\
\text { atividades físicas } \\
\text { e/ou coletivo tanto } \\
\text { no esporte quanto } \\
\text { em outros programas } \\
\text { de atividades físicas } \\
\text { orientados por } \\
\text { Profissionais de } \\
\text { Educação Física; }\end{array}$ \\
\hline Características & Características & Características & Características & Características & \\
\hline $\begin{array}{l}\text { Art. } 3 \\
\text { VII- }\end{array}$ & $\begin{array}{l}\text { Art. } 3 \\
\text { IX- }\end{array}$ & $\begin{array}{l}\text { Art. } 3 \\
\text { X- }\end{array}$ & $\begin{array}{l}\text { Art. } 3 \\
\text { XI- }\end{array}$ & $\begin{array}{l}\text { Art. } 3 \\
\text { XII- }\end{array}$ & \\
\hline $\begin{array}{l}\text { Identificar as } \\
\text { causas primárias: } \\
\text { baixa capacidade } \\
\text { de adaptação a } \\
\text { competições } \\
\text { muito exigentes e } \\
\text { frequentes, } \\
\text { recuperação } \\
\text { insuficiente, } \\
\text { fatores } \\
\text { psicológicos; e as } \\
\text { causas } \\
\text { secundárias: } \\
\text { nutricionais, } \\
\text { infecciosas, } \\
\text { ambientais, entre } \\
\text { outras, } \\
\text { Overtraining; do }\end{array}$ & $\begin{array}{l}\text { Dirigir, } \\
\text { coordenar, } \\
\text { supervisionar, } \\
\text { atletas/equipes } \\
\text { esportivas; }\end{array}$ & $\begin{array}{l}\text { Dirigir, coordenar, } \\
\text { supervisionar e } \\
\text { ministrar } \\
\text { atividades para } \\
\text { indivíduos/grupos } \\
\text { com diferentes } \\
\text { condições de } \\
\text { saúde e de } \\
\text { condicionamento } \\
\text { físico, incluindo os } \\
\text { diferentes tipos de } \\
\text { recuperação; }\end{array}$ & $\begin{array}{l}\text { Prestar serviços } \\
\text { de consultoria, } \\
\text { auditoria } \\
\text { assessoria na } \\
\text { área de sua } \\
\text { Especialidade; }\end{array}$ & $\begin{array}{l}\text { Desenvolver } \\
\text { pesquisa } \\
\text { científica } \\
\text { tecnológica na } \\
\text { área de sua } \\
\text { Especialidade. }\end{array}$ & \\
\hline
\end{tabular}

Fonte: Autores.

O presente quadro traz competências e reponsabilidades do PEDF, ele dispõe sobre Especialidade Profissional em Educação Física na área de Treinamento esportivo/físico. Logo depois é momento de relacionar e identificar quais ações enquadram-se na lei de direitos autorais. Para tanto, segue abaixo mapa 1 com as obras intelectuais que são expressas e fixadas 
com protegíveis na Lei $\mathrm{N}^{\circ}$ (9609/98), título II das obras intelectuais, capítulo I das obras protegíveis em seu artigo $7^{\circ}$ do primeiro ao $13^{\circ}$ parágrafo.

Figura 1: Direitos autorais.

\begin{tabular}{|c|c|c|}
\hline & 1- & Os textos de obras literárias, artisticas ou cientificas; \\
\hline & ॥- & Ass conferências, alocuçōes, sermōes e outras obras da mesma natureza; \\
\hline & III & As conferências, alocuçōes, sermŏes e outras obras da mesma natureza, \\
\hline \multirow{10}{*}{$\begin{array}{c}\text { Lei } \\
N^{\circ} \\
(960 \\
9 / 98) \\
\text { Artig } \\
\circ 7^{\circ}\end{array}$} & IV & As conferências, alocuçōes, sermőes e outras obras da mesma natureza; \\
\hline & V & As composiçס̄es musicais, tenham ou nāo letra; \\
\hline & VI & As obras audiovisuais, sonorizadas ou năo, inclusive as cinematograficas: \\
\hline & VII & As obras fotograficas e as produzidas por qualquer processo análogo ao da fotografia: \\
\hline & VIII & As obras de desenho, pintura, gravura, escultura, itografia e arte cinética; \\
\hline & IX & As ilustraç̋es, cartas geográficas e outras obras da mesma natureza: \\
\hline & $x$ & $\begin{array}{l}\text { Os projetos, esboços e obras plásticas concernentes à geografia, engenharia, topografia, arquitetura, } \\
\text { paisagismo, cenografia e ciência, }\end{array}$ \\
\hline & $\mathrm{XI}$ & 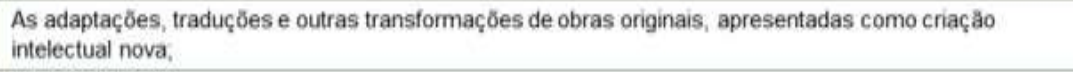 \\
\hline & XII & Os programas de computador; \\
\hline & XIII & $\begin{array}{l}\text { As coletâneas ou compilaçס̄es, antologias, enciclopedias, dicionários, bases de dados e outras obras, que, } \\
\text { por sua seleção, organizaçăo ou disposiçăo de seu conteúdo, constituam uma criaçăo intelectual. }\end{array}$ \\
\hline
\end{tabular}

Fonte: Ramos et al (2021).

Em consonância com a Lei $N^{\circ}$ (9609/98) de direitos autorais do Brasil, o presente mapa traz em evidência o capítulo II que dispõe sobre quais obras são protegidas. Tomando como base a presente lei e artigo, é momento de relacionar os produtos aqui protegidos com as ações dos PEDF apresentadas no quadro1.

Em suma, temos na resolução CONFEF nº 327/2016 que, enquanto ação do profissional de Educação Física, compete a este: planejar, elaborar, orientar, descrever, pesquisar, prestar consultoria, dirigir, coordenar, supervisionar, analisar, dosar volume e intensidade, avaliar, reavaliar, prescrever, acompanhar a evolução e necessidade de seu cliente, aluno ou paciente. Ações e elementos esses que não aparecem na Lei $\mathrm{N}^{\circ}$ (9609/98) como passivo de proteção. No entanto, no conjunto de sua atuação o PEDF gera um produto, sendo esse o elemento que possa apresentar características de proteção na lei dos direitos autorais. Assim, vale destacar o artigo $3^{\circ} \mathrm{em}$ seu IV parágrafo, onde aponta que é atribuição do PEDF planejar, organizar e estruturar os processos de treinamento.

Tal informação reforça a ideia que o PEDF, a cada objetivo, finalidade e cliente, precisa customizar, modelar, periodizar variações no programa estabelecido (Tozzeto, 2020). Os programas, periodizações e seções podem ser entendidas como a sistematização de ações motoras relacionadas e condicionadas às alterações e comportamento do praticante, sendo estruturados em etapas e objetivos diferentes, tendo ainda especificidades correlacionadas a um produto final do aluno/cliente (Celi; Panda, 2014). Logo, em sua ação profissional, o PEDF chega a um construto em modelo de produto. A indagação agora é: tal produto enquadra-se na proteção dos direitos autorais? Essa é uma discussão inicial e sua resposta requer um 
aprofundamento maior em termos legais. Refletindo, inicialmente, sobre a pergunta é possível traçar uma hipótese e levantar o tema para debates e discussões.

Dando continuidade a comparação e construção da hipótese frente a pergunta levantada, é relevante analisar o parágrafo X, do artigo $7^{\circ}$ da Lei $\mathrm{N}^{\circ}$ (9609/98) apresentada no mapa 1. Em sua descrição é possível destacar que "os projetos, esboços e obras plásticas concernentes à geografia, engenharia, topografia, arquitetura, paisagismo, cenografia e ciência" são enquadrados na proteção autoral. Em linhas gerais, se um projeto arquitetônico ou científico traz elementos e características de proteção, é possível de maneira embrionária perceber elementos nos projetos, programas e seções de treinamento que se engajem na mesma esfera. Pois, como exposto no artigo $3^{\circ}$, do parágrafo IV da resolução CONFEF $n^{\circ}$ 327/2016, fica expresso que o PEDF gera projeto, programa e produto em sua função.

Após essa comparação entre a CONFEF no 327/2016 e a Lei $N^{\circ}$ (9609/98), buscando identificar elementos caracterizados na atuação do profissional de Educação Física e a possível proteção dos direitos autorais, é necessário refletir sobre o que não é passivo de proteção, fundamentado e apresentado na mesma Lei $\mathrm{N}^{\circ}$ (9609/98) em seu artigo $8^{\circ}$. Assim, abaixo teremos o mapa 2, onde será apresentado os itens e produtos que não podem ser protegidos pelos direitos autorais.

Figura 2: O que não se protege mediante direito autoral.

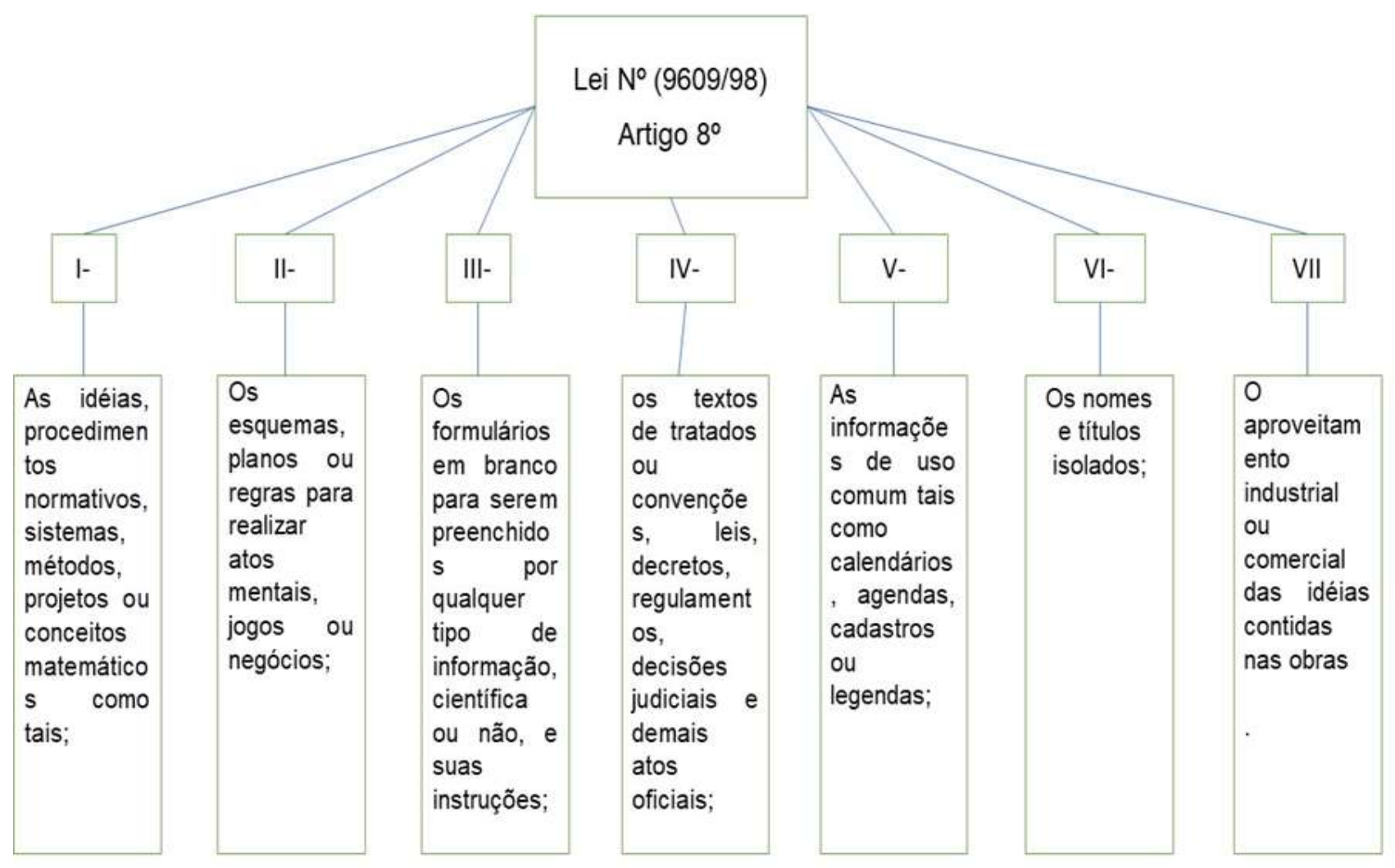

Fonte: Ramos et al (2021).

Aqui temos os sete parágrafos do artigo $8^{\circ}$ da Lei $\mathrm{N}^{\circ}$ (9609/98), que trata sobre os produtos e objetos que não podem ser protegidos. No primeiro parágrafo temos o veto a métodos, projetos, conceitos ou normas, até então instrumentos distintos dos programas de treinamento. No segundo parágrafo versa sobre esquemas, planos, regras, atos mentais, jogos e ainda negócios, ações também não atribuídas às seções de treinamento, já no terceiro aborda-se sobre protocolos, planos, documentos em branco. Até aqui nada que iniba a proteção de um possível modelo de seções treinamentos, no quarto e quinto é discutido sobre textos, calendários, convenções, decisões judiciais, legendas e cadastros. Informações que ainda não 
restringem os programas ou periodização do treinamento. Por fim, o sexto e sétimo parágrafo, tendo como proibições nomes, títulos e aproveitamento das ideias em textos. Se relacionado ao produto programa de treinamento, diretamente não há restrições para a concessão do reconhecimento dos direitos autorais perante o programa de treinamento. Logo, levantar inquietações sobre a pertinência de requerer proteção autoral parece ser em tese possível e discutível, contudo um aprofundamento sobre o tema se faz necessário.

\section{Caracterização dos modelos, periodização e seções da atividade física: Elementos e critérios para modelar o treinamento}

Quando se pensa em organizar um período, uma seção ou um ciclo de treinamento, seja com fins profiláticos ou terapêuticos, o profissional responsável precisa conhecer e dominar uma série de saberes, de cunho conceitual, procedimental e atitudinal, além de customizar de acordo com os objetivos e características de seu aluno/cliente. Pois, periodizar é o ato de organizar detalhadamente todas as variantes do treinamento, levar em consideração os objetivos do praticante, bem como aplicar os princípios científicos da ciência do treinamento (Oliveira, 2003).

Em sua história, a humanidade sempre buscou compreender os aspectos básicos do fortalecimento corporal, resistências, saúde ou estética. Em sua jornada, destaca-se ainda a preparação do corpo para combates e manutenção da saúde, levando assim pesquisadores e profissionais da saúde a buscar por maiores informações perante os impactos da atividade física e saúde (Dantas, 2011). É por meio desse interesse que hoje a atividade física e a saúde estão intrinsicamente conectadas, e estruturar o treino é fundamental para alcançar os objetivos esperados.

Na montagem da seção do treinamento, seja a curto ou longo prazo, o PDEF leva em consideração alguns princípios, que são: individualidade da carga, respeitando e considerando as especificidades biológicas, no que diz respeito às respostas ao estímulo. Alinhar a intensidade-volume aos períodos e etapas do treinamento, acompanhar a progressão por meio de avaliações e adaptação de novos estímulos, exigindo uma customização constante, considerar os objetivos do praticante e modificar, estruturar volume-carga de acordo com o período e monitorar os impactos do treinamento mediante as finalidades requisitadas (Neiva, 2019).

Ainda sobre a customização do treinamento e prescrição da atividade física, o PDEF precisa levar em consideração os aspectos de saúde relacionados aos componentes cardiorrespiratórias, à força e à resistência muscular, flexibilidade, estimulação neuro-motora, lesões, histórico de vida, nível de condicionamento, condições socioeconômicas e nível de satisfação e gosto sobre as práticas corporais (Nahas, 2001). Percebe-se, então, que antes de montar todo o processo/produto, o PDEF precisa coletar uma série de informações, para assim modelar todo o desenho da arte.

Tentando especificar um pouco mais a prescrição de atividade física num contexto de promoção da saúde, esta deve estar imbuída de embasamento científico, ser individualizada, caracterizar a arte do treinamento, promover alterações fisiológicas, diferenciar as finalidades, os campos de aplicação, ter domínio antropométrico, cinesiológico, compreender o grau e nível da aptidão física do aluno/cliente, entender as dimensões da composição corporal, capacidade aeróbica, resistência muscular e flexibilidade. Além de aplicar constantemente avaliação com objetividade de ter um prognóstico e traçar todo o programa e período do treinamento, seção ou ciclos, mantendo esse processo constantemente (Medeiros, 2017). Logo, a atividade física sistematizada que gera o exercício físico demanda em sua essência produção intelectual, integração de saberes e construção de produto.

Discutir atividade física e a atuação do profissional de Educação Física em pleno século XXI, em um período em que a humanidade é impactada pela COVID-19, é fundamental para identificar possibilidades que estimulem ainda mais esses profissionais. Assim, sistematizar e padronizar elementos que tornem a recriação da atividade física independentemente de sua 
finalidade pode ser necessário para consolidar a valorização do PDEF e repensar os modelos aleatórios para prescrição da atividade.

Trazer a atividade física enquanto necessária para saúde pública mostra ainda mais a relevância desse tema. Pois, a atividade física na contemporaneidade pode ser caracterizada como prática estruturada e sistematizada, prescritiva e orientada por profissionais da educação física, ocupando grande destaque e cenário na saúde mundial (CAMPOS, 2021).

Assim, para modelar e estruturar um programa de treinamento, o PDEF, além de aplicar todos os conceitos até aqui apresentados, precisa entregar um produto ao seu cliente, o programa detalhado das atividades, exercícios, ciclos, estímulos, períodos e volume e intensidade são alguns dos elementos. Logo, temos aqui características de uma modelagem de treinamento, estrutura de um projeto a ser desenvolvido de forma individualizada e pensada mediante as necessidades do requerente.

No processo de modelagem este pode ser entendido como o agrupamento de informações, baseado numa abordagem padronizada por objetivos e finalidades com perspectiva na construção de projeto, programa ou produto. Na modelagem se descreve e estabelece uma série de caminhos para construir o modelo esperado (Rumbaugh, 1994). Nesta perspectiva, é possível perceber as relações da modelagem com a sistematização dos programas e/ou seções de treinamento, além das similaridades, os passos e princípios de construção.

Outro caminho a ser destacado referente a modelagem é o aplicado na arquitetura, que traz a modelagem de projetos por meio de informações técnicas e específicas para a sua montagem, e que devem ser incorporadas aos projetos, traz também que é necessário coletar algumas informações, como custos, prazos, especificações do cliente, dados do fabricante e parâmetros de desempenho na construção (Junior \& \& Mitidieri Filho). Logo, mais uma vez é possível notar informações inerentes aos programas de atividade física estruturada, além de relação com o artigo $7^{\circ}$ no parágrafo $X$ da lei $\mathrm{N}^{\circ}$ (9609/98) de direitos autorias e o que lhe são conexos expressa neste estudo.

Pensar a modelagem dos projetos, seções e programas de treinamento como produtos, parece ser viável, levantar esta temática no cenário científico e legais pode contribuir com a transformação e ressignificação da atuação do profissional em Educação Física.

Abaixo será apresentado o mapa 3, trazendo e apresentado as relações e conexões entre os programas, modelagem, seções e ou programas de treinamento, além de sua intrínseca conexão com a lei dos direitos autorais. 
Figura 3: Relação modelagem de projetos e seção de treinamento.

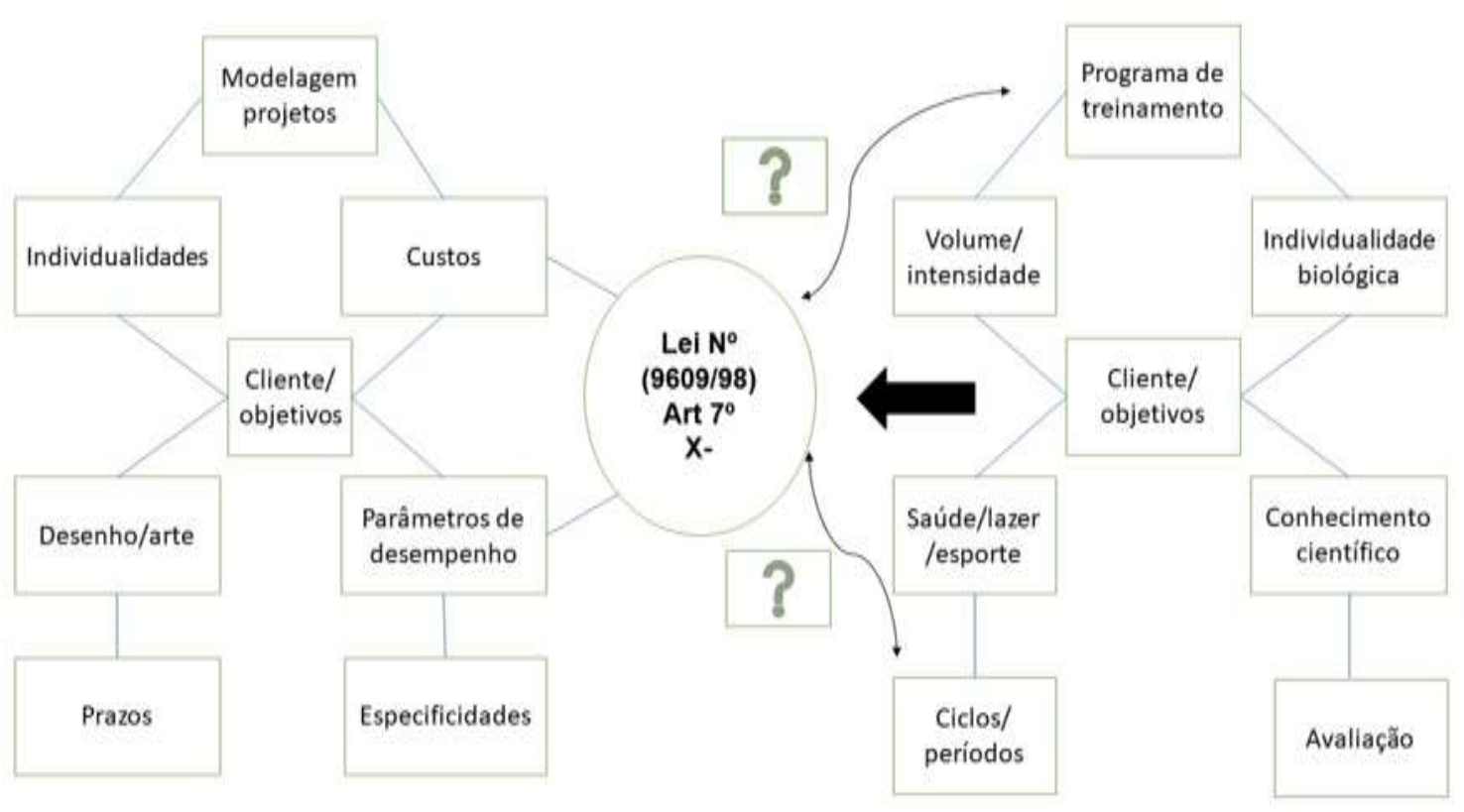

Fonte: Ramos et al (2021).

De modo geral, é perceptível relações e semelhanças entre os dois produtos gerados, principalmente, no quesito conhecimentos necessários para pensar o projeto e informações necessárias para a montagem e modelagem de ambos. Em sua função, o PFDE aplica e constrói elementos característicos apresentados no $7^{\circ}$ artigo do parágrafo $\mathrm{X}$ dos direitos autorais. $\mathrm{O}$ mapa ilustra elementos como individualidade do sujeito, condições e especificidades do produto, além do construto final, o projeto.

Com isso, pode-se enfatizar que existem elementos na ação do profissional de Educação Física inerentes aos projetos de características científicas destacados na lei de propriedade intelectual, cabendo assim reflexões e discussões frente essa temática.

Após o presente estudo surge a necessidade de novas pesquisas e debates sobre este tema, uma análise sistemática pode ser interessante para aumentar as evidências e relações entre a atuação do PFDF e o produto construído com a customização dos treinamentos, seja com fins profiláticos ou terapêuticos.

\section{Conclusão}

Após análise documental aplicada no presente estudo, foi possível identificar que a atividade física é caracterizada como ação motora que proporciona gasto energético, e por meio de seus princípios surge a atividade física sistematizada e/ou exercício físico, que, por sua vez, é planejada, elaborada, construída, customizada e produzida por um profissional de Educação Física. Esse precisa de domínios técnicos científicos para a estruturação dos programas de treinamento, precisando levar em considerações elementos como individualidade biológica do aluno/cliente, objetivos, saberes do treinamento, volume, intensidade, alterações biológicas internas, cinesilógicos, biomecânicos, perimetria, ciclos, períodos, avaliação e finalmente o produto modelo/cessão de treinamento.

Evidencia-se também que a lei $\mathrm{N}^{\circ}$ 9609/98 no artigo $7^{\circ}$ do parágrafo $X$ de direitos autorias e o que lhe são conexos destaca projetos e outros produtos como passivo de proteção autoral, nele é possível observar ainda que esboços e projetos, frutos de áreas como geografia, engenharia, paisagismo, arquitetura, entre outros, são passivos de proteção autoral. 
Foi possível identificar ainda que a Resolução CONFEF n 327/2016: Art. 2º que versa sobre a atuação do profissional de Educação Física no contexto do treinamento e prescrição de atividade física, aborda enquanto competência deste profissional planejar, elaborar, construir e avaliar projetos, seções, periodização e modelos de treinamento, sendo este elemento produto final no processo de construção do ciclo de treinamento.

Comparando e analisando a lei $\mathrm{N}^{\circ}$ 9609/98 no artigo $7^{\circ}$ do parágrafo $X$ de direitos autorias e o que lhe são conexos e a Resolução CONFEF n 327/2016, Art. 2º foi encontrado que o produto produzido pelo profissional de Educação Física em sua atuação, enquanto propriedade intelectual, apresenta características similares às protegíeis pela lei de direitos autorais, principalmente na similaridade apresentada entre modelagem de projetos e construção das seções de treinamento, como objetivos, etapas, finalidades e construto final.

Seja por fins profiláticos ou terapêuticos o profissional de Educação Física demanda construção e elaboração de seções de treinamento e projeto detalhado de treinamento, devendo especificar tempo, volume, intensidade, calcular variações e remodelar o projeto de acordo com o objetivo de cliente ou atleta, sendo esse o seu produto final, e propriedade intelectual.

Durante este estudo, buscou-se levantar informações quanto à atuação do profissional de educação física, caracterizar a atividade física, analisar a lei $N^{\circ}$ 9.609/98 e a resolução CONFEF n ${ }^{\circ}$ 327/2016 e comparar a seção de treinamento, projeto de treinamento com os elementos e critérios de proteção autoral. Identificando assim, que no processo de modelagem de projetos e periodização do treinamento existe similaridades, despertando aí a necessidade de aprofundar mais estudos sobre essa temática. Pois, dar autoria e créditos aos produtos construídos pelos profissionais de Educação Física pode provocar alterações na atuação deste profissional e ainda potencializar a valorização da prescrição de atividade física sistematizada, trazendo ganhos para a sociedade de maneira geral.

Por fim, a atividade física é objeto de estudo de inúmeras áreas da saúde, muitas vezes apresentada enquanto "remédio", mas é se destacando enquanto ação preventiva que possui relevância perante diminuição das enfermidades oriundas da inatividade física, como doenças cardiovasculares, psicossomáticas, obesidade e entre outras apresentadas neste estudo e impactando ainda diretamente no setor saúde. Quando orientada potencializa seus benéficos e reduz os riscos de lesões, sendo ainda recomendada por diversos profissionais da saúde, tendo seus benefícios já comprovados. Logo, existe aí a necessidade de buscar a valorização do profissional responsável pela prescrição do treinamento, dar autoria de seu produto, propriedade intelectual e estimular a produção de modelos e projetos passíveis de reprodução, seja com fins profiláticos ou terapêuticos.

É relevante sinalizar a necessidade de novos estudos afim de aprofundar e fomentar a discussão sobre a presente temática. Discutir a atuação e valorização do profissional de Educação Física pode trazer impactos positivos para a profissão e sociedade de maneira geral. Com isso, se os profissionais da área podem despertar interesse e apresentar ou levantar pautas relacionadas a proteção de projetos, planos e seções de treinamento, além de existir a possibilidade de surgir novas especificidades com novos estudos.

\section{Referências}

De Campos, A. L., Batista, C. L., de Almeida, D. R., \& Garcia, S. M. (2021). Primíparas Investigadas quanto a atividade física em uma Estratégia da Saúde da Família (ESF). Brazilian Journal of Health Review, 4(1), 1761-1781. https://www.brazilianjournals.com/index.php/BJHR/article/view/23612>.

Carmo, A. P. D. (2018). Atividade física na gestação e lactação (Bachelor's thesis). < https://attena.ufpe.br/handle/123456789/28965>.

De Educação Física, C. F. (2009). CONFEF. Educação física escolar. http://www.crefsc.org.br/principal/wpcontent/uploads/2016/04/intervencao_profissional_de_ef.pdf>.

Costa, R. A., Soares, H. L. R., \& Teixeira, J. A. C. (2007). Benefícios da atividade física e do exercício físico na depressão. Revista do Departamento de Psicologia. UFF, 19(1), 273-274. https://www.scielo.br/scielo.php?pid=S010480232007000100022\&script=sci_arttext\&tlng=ES.

Celi, J. A., \& Panda, M. D. J. (2014). Efeito de um programa personalizado de exercícios físicos na composição corporal: um estudo de caso.< https://home.unicruz.edu.br/mercosul/pagina/anais/2014/DIREITO\%20AO\%20MAIS\%20ALTO\%20PATAMAR\%20DE\%20SAUDE\%20FISICA\%20E\%20 MENTAL/ARTIGO/ARTIGO\%20- 
\%20EFEITO\%20DE\%20UM\%20PROGRAMA\%20PERSONALIZADO $\% 20 \mathrm{DE} \% 20$ EXERCICIOS\%20FISICOS\%20NA\%20COMPOSICAO\%20CORPOR AL\%20UM\%20ESTUDO\%20DE\%20CASO.PDF>.

Dantas, E. H. M., Godoy, E. S. D., Sposito-Araujo, C. A., Oliveira, A. L. B. D., Azevedo, R. C., Tubino, M. J. G., \& Gomes, A. C. (2011). Adequabilidade dos principais modelos de periodização do treinamento esportivo. Revista Brasileira de Ciências do Esporte, 33(2), 483-494. https://www.scielo.br/scielo.php?pid=S0101-32892011000200014\&script=sci_arttext\&tlng=pt $>$.

Dias, A. F., Mello, J. B., Teodoro, J. L., Gaya, A., \& Gaya, A. R. (2017). Ocorrência e associação entre sobrepeso/obesidade E níveis de atividade física de escolares. RBPFEX-Revista Brasileira De Prescrição $\quad$ D $\quad$ Fisiologia Do Exercício, 11(70), 871879:http://scholar.googleusercontent.com/scholar?q=cache:sNgUPVXykzEJ:scholar.google.com/+A+prescri\%C3\%A7\%C3\%A3o+da+atividade+f\%C3\%ADsi ca\&hl=pt-BR\&as_sdt=0,5\&as_ylo=2017>.

Estrela, A. L., \& Bauer, M. E. (2017). Envelhecimento saudável e atividade física: uma revisão sistemática sobre os efeitos do exercício nas doenças cardiovasculares. Scientia Medica, 27(1), 4. https://dialnet.unirioja.es/servlet/articulo?codigo=5907018>.

Gurge, D. C., Nogueira, I. C., \& Neto, P. P. (2018). Atividade física e câncer: intervenções nutricionais para um melhor prog nóstico. Motricidade, 14(1), 398404. https://search.proquest.com/openview/e78b764963d2959a3afc3ec8fc6a1e6a/1?pq-origsite=gscholar\&cbl=616555>.

Junior, M. A. S., \& Mitidieri Filho, C. V. (2018). Verificação de critérios de desempenho em projetos de arquitetura com a modelagem BIM. PARC Pesquisa em Arquitetura e Construção, 9(4), 334-343. https://periodicos.sbu.unicamp.br/ojs/index.php/parc/article/view/8650453.

Leroy, M. H. C., \& da Rocha Reis, A. Reforma da lei de direito autoral em razão das novas tecnologias e modelos de negócios na internet. anais xiii codaip, 129.

http://scholar.googleusercontent.com/scholar?q=cache:LZmmBs3_46UJ:scholar.google.com/+direitos+autorais+Brasil+conven\%C3\%A7\%C3\%A3o+de+Bern a\&hl=pt-BR\&as_sdt=0,5\&as_ylo=2020\&as_vis $=1>$

Lopes, C., Torres, D., Oliveira, A., Severo, M., Alarcão, V., Guiomar, S., \& Ramos, E. (2017). Inquérito Alimentar Nacional e de Atividade Física IAN-AF 2015-2016: relatório de resultados. https://repositorio-aberto.up.pt/bitstream/10216/111073/2/257104.pdf>.

Luna, C. F., \& Rocha, K. S. (2020). O currículo em educação física: mudanças paradigmáticas, políticas e legislativas. Cenas Educacionais, 3, e9914-e9914. < https://www.revistas.uneb.br/index.php/cenaseducacionais/article/view/9914>.

Magalhães, R. I. C. (2017). Prescrição de atividade física em idosos hipertensos (Doctoral dissertation). < https://ubibliorum.ubi.pt/handle/10400.6/8085> .

Matsudo, S. M., \& Matsudo, V. K. (2008). Prescrição e benefícios da atividade física na terceira idade. Revista Brasileira de Ciência e Movimento, 6(4), 1930. < https://portalrevistas.ucb.br/index.php/RBCM/article/viewFile/225/384>

Medeiros, L. H. D. L. (2017). Comparação entre modelos de periodização do treinamento físico combinado (aeróbico e resistido) em mulheres de 50 a 75 anos de idade: associação com variantes genéticas (Doctoral dissertation, Universidade de São Paulo) < https://www.teses.usp.br/teses/disponiveis/17/17138/tde-23042018-111352/en.php>

Medina, F. L., Lobo, F. D. S., Souza, D. D., Kanegusuku, H., \& Forjaz, C. D. (2010). Atividade física: impacto sobre a pressão arterial. Rev Bras Hipertens, 17(2), 103-106. http://departamentos.cardiol.br/dha/revista/17-2/10-atividade.pdf

Mercuri, N., \& Arrechea, V. (2001). Atividade física e diabetes mellitus. Diabetes Clínica, 5(2), 347-349. https://www.researchgate.net/profile/Claudio-GilAraujo/publication/200138040_Diabetes_mellitus_e_atividade_fisica/links/0046352eca712e30a7000000/Diabetes-mellitus-e-atividade-fisica.pdf>.

Minayo, M. C. D. S. (1989). O desafio do conhecimento: metodologia de pesquisa social (qualitativa) em saúde. https://pesquisa.bvsalud.org/portal/resource/pt/lil-98820

Nahas, M. V. (2001). Atividade física, saúde e qualidade de vida. Londrina: Midiograf, 3, 278. https://sbafs.org.br/admin/files/papers/file_IIduWnhVZnP7.pdf>.

Neiva, H. P. (2019). Princípios gerais da prescrição do exercício. Documento de apoio ao mestrado em exercício e saúde. https://scholar.googleusercontent.com/scholar?q=cache:gTLLoGGyGIcJ:scholar.google.com/+principios+para+periodizar+o+treino\&hl=pt-

BR\&as_sdt $=0,5 \&$ as_ylo $=2017>$

Oliveira, A. L. B. D., Sequeiros, J. L. D. S., \& Dantas, E. H. M. (2005). Estudo comparativo entre o modelo de periodização clássica de Matveev e o modelo de periodização por blocos de Verkhoshanski. https://openrit.grupotiradentes.com/xmlui/handle/set/519.

Panzolini, C. R. L. D. (2018). Direitos autorais: aspectos essenciais e tendências. < https://repositorio.unb.br/bitstream/10482/34485/ 1/2018_CarolinaRaquelLeiteDinizPanzolini.pdf>.

Roschel, H., Tricoli, V., \& Ugrinowitsch, C. (2011). Treinamento físico: considerações práticas e científicas. Revista Brasileira de Educação Física e Esporte, 25(SPE), 53-65. https://www.scielo.br/scielo.php?pid=S1807-55092011000500007\&script=sci_arttext>

Rumbaugh, J., Blaha, M., Premerlani, W., Eddy, F., \& Lorensen, W. (1994). Modelagem e projetos baseados em objetos (Vol. 8). http://www.sidalc.net/cgi$\mathrm{bin} / \mathrm{wxis}$.exe/?IsisScript=ACERVO.xis\&method=post \& formato $=2 \&$ cantidad $=1 \&$ expresion $=\mathrm{mfn}=041522>$.

Souza Filho, B. A. B. D., \& Tritany, É. F. (2020). COVID-19: importância das novas tecnologias para a prática de atividades físicas como estratégia de saúde pública. Cadernos de Saúde Pública, 36, e00054420.

Tozetto, W. R. (2020). Efeitos da periodização do treinamento combinado na qualidade de vida relacionada à saúde e sua relação com indicadores antropométricos em adultos com obesidade: um ensaio clínico randomizado. https://repositorio.ufsc.br/handle/123456789/216437>. 